\title{
Effect of inhibition of nitric oxide synthase on blood pressure and renal sodium handling in renal denervated rats
}

A.M. Xavier, A.M.F. Magalhães and J.A.R. Gontijo
Disciplina de Medicina Interna, Laboratório Balanço Hidro-Salino, Núcleo de M edicina e Cirurgia Experimental, D epartamento de Clínica Médica, Faculdade de Ciências M édicas, Universidade Estadual de Campinas, Campinas, SP, Brasil

\section{Correspondence \\ J.A.R. Gontijo \\ Departamento de Clínica Médica \\ Faculdade de Ciências Médicas \\ UNICAMP \\ 13083-100 Campinas, SP \\ Brasil \\ Fax: +55-19-788-8861 \\ E-mail: gontijo@ nmce.unicamp.br \\ Research partially supported by CNPq (No. 500868/91-3) and FAPESP (No. 95/1299-0).}

Received April 16, 1999 Accepted January 11, 2000

\section{Abstract}

The role of sympathetic nerve activity in the changes in arterial blood pressure and renal function caused by the chronic administration of $\mathrm{N}^{\mathrm{G}_{-}}$ nitro-L-arginine methyl ester (L-NAME), an inhibitor of nitric oxide (NO) synthesis, was examined in sham and bilaterally renal denervated rats. Several studies have demonstrated that sympathetic nerve activity is elevated acutely after L-NAME administration. To evaluate the role of renal nerve activity in L-NAME-induced hypertension, we compared the blood pressure response in four groups $(\mathrm{N}=10$ each) of male WistarHannover rats weighing 200 to $250 \mathrm{~g}: 1$ ) sham-operated vehicle-treated, 2) sham-operated L-NAME-treated, 3) denervated vehicle-treated, and 4) denervated L-NAME-treated rats. After renal denervation or sham surgery, one control week was followed by three weeks of oral administration of L-NAME by gavage. Arterial pressure was measured weekly in conscious rats by a tail-cuff method and renal function tests were performed in individual metabolic cages $0,7,14$ and 21 days after the beginning of L-NAME administration. L-NAME (60 mg kg-1 day $\left.{ }^{-1}\right)$ progressively increased arterial pressure from $108 \pm 6.0$ to $149 \pm 12$ $\mathrm{mmHg}(\mathrm{P}<0.05)$ in the sham-operated group by the third week of treatment which was accompanied by a fall in creatinine clearance from $336 \pm 18$ to $222 \pm 59 \mu 1$ min $^{-1} 100$ g body weight $^{-1}(\mathrm{P}<0.05)$ and a rise in fractional urinary sodium excretion from $0.2 \pm 0.04$ to $1.62 \pm 0.35 \%$ $(\mathrm{P}<0.05)$ and in sodium post-proximal fractional excretion from $0.54 \pm$ 0.09 to $4.7 \pm 0.86 \%(\mathrm{P}<0.05)$. The development of hypertension was significantly delayed and attenuated in denervated L-NAME-treated rats. This was accompanied by a striking additional increase in fractional renal sodium and potassium excretion from $0.2 \pm 0.04$ to $4.5 \pm 1.6 \%$ and from $0.1 \pm 0.015$ to $1.21 \pm 0.37 \%$, respectively, and an enhanced postproximal sodium excretion compared to the sham-operated group. These differences occurred despite an unchanged creatinine clearance and $\mathrm{Na}^{+}$ filtered load. These results suggest that bilateral renal denervation delayed and attenuated the L-NAME-induced hypertension by promoting an additional decrease in tubule sodium reabsorption in the postproximal segments of nephrons. Much of the hypertension caused by chronic NO synthesis inhibition is thus dependent on renal nerve activity.

\section{Key words}

- Nitric oxide

- Hypertension

- Natriuresis

- Renal denervation

- Lithium clearance 


\section{Introduction}

The endothelium is the major source of nitric oxide (NO) which plays an important role in local circulatory control $(1,2)$. Uncontrolled hypertension with associated endothelial damage increases cardiovascular morbidity and mortality and leads to progressive renal functional impairment in essential hypertension (3). Experimental models of renal disease with hypertension, including renal failure in rats, normally require nephrectomy and extirpation of tissue from the contralateral kidney, renal infarction, or the use of nephrotoxic drugs or chemicals to produce significant hypertension $(4,5)$. As a result, extrapolation from such studies to patients with essential hypertension who have two normally functioning kidneys seems inappropriate. A better laboratory model is therefore essential for an accurate understanding of the pathophysiological progression and renal involvement occurring in hypertension.

Several studies have shown that shortterm administration of an NO synthase (NOS) inhibitor results in a prompt increase in the arterial pressure of rats, rabbits, and dogs (6$8)$. The immediate increase in arterial pressure mainly reflects an increased vascular smooth muscle tone as a consequence of decreased NO synthesis. Increases in sympathetic nerve activity have been described after acute inhibition of NO synthesis (610 ), suggesting that neurogenic mechanisms may contribute to the rise in arterial pressure.

Chronic intravenous infusion of the NO synthesis inhibitor $\mathrm{N}^{\mathrm{G}}$-nitro-L-arginine methyl ester (L-NAME) also causes sustained hypertension in dogs and rats (11-13) associated with increased renal vascular resistance, glomerular filtration rate and urinary sodium excretion. Additionally, the natriuretic effects of arterial pressure on urinary sodium excretion in anesthetized dogs have recently been shown to be significantly attenuated during L-NAME administration (14-16).

Although the precise mechanism by which continued NO synthesis inhibition induces chronic hypertension remains to be identified, renal control of the fluid and electrolyte balance is thought to play a dominant role in the long-term control of arterial pressure in both normal and pathophysiological states $(6-8,14)$. Renal sympathetic nerve activity increases after inhibition of NO synthesis $(10,13)$ and the activation of these nerves inhibits renal sodium excretion and promotes renal renin secretion (11). However, the long-term changes in renal sodium tubule handling associated with L-NAMEinduced hypertension in rats have not been examined in detail. We hypothesized that chronic L-NAME-induced hypertension may result partly from sustained renal sympathetic nerve activation and a consequent decrease in renal sodium excretion. To test this hypothesis, we investigated the effects of chronic oral administration of L-NAME on the arterial pressure and tubule sodium handling of renal denervated rats and their shamoperated controls.

\section{Material and Methods}

The experiments were performed on male Wistar-Hannover rats (200-250 g) allowed free access to water and normal rat chow. To examine the influence of renal denervation during the administration of L-NAME the rats were assigned randomly to one of four groups ( $\mathrm{N}=10$ each): 1) sham-operated vehicle-treated, 2) sham-operated L-NAMEtreated, 3) denervated vehicle-treated, and 4) denervated L-NAME-treated rats. The general guidelines established by the Declaration of Helsinki (1964) for laboratory animals were followed throughout the study.

\section{Experimental design}

The experiments consisted of one control week followed by three weeks of oral admin- 
istration of L-NAME $\left(60 \mathrm{mg} \mathrm{kg}^{-1}\right.$ day $\left.^{-1}\right)$ or vehicle by gavage. Arterial pressure was estimated weekly in conscious, restrained rats by the tail-cuff method using an electrosphygmomanometer (Narco Bio-Systems, Austin, TX, USA). On the last day of each week (control week (0) and 7, 14 and 21 days after beginning L-NAME administration), the rats were weighed and housed in individual metabolic cages to measure urinary flow rate and protein excretion over a 14-h period. Renal function tests were also performed.

Fourteen hours before the renal test, 60 $\mathrm{mmol} \mathrm{LiCl} / 100 \mathrm{~g}$ body weight was given by gavage. The rats were subsequently housed individually in metabolic cages with free access to tap water but no food. The experiment was performed at the same time in each group of sham-operated (vehicle or LNAME-treated) and denervated (vehicle or L-NAME-treated) rats. At 8:00 a.m., each rat received a tap water load ( $5 \%$ of body weight) by gavage followed by a second load of the same volume $1 \mathrm{~h}$ later. Twenty minutes after the second load, spontaneously voided urine was collected over a 2 -h period. The voided urine passed through the funnel in the bottom of a cage into a graduated centrifuge tube. At the end of the experiment, blood samples were drawn by cardiac puncture and the kidney was immediately removed, decapsulated and weighed.

\section{Renal denervation}

After dorsal abdominal incisions, both kidneys were exposed and surgically denervated with the aid of a stereomicroscope in rats anesthetized with pentobarbital sodium (30-50 mg/kg, ip). Denervation was accomplished by cutting all visible nerves along the renal artery and by stripping the nervous and connective tissue passing along the course of the renal artery and vein. Immediately thereafter, the renal vessels were wrapped with cotton previously soaked in $10 \%$ (v/v) phe- nol diluted with absolute ethanol (17). Shamoperated rats underwent all of the surgical procedures except that the renal artery was left intact. The rats were used 1 week after renal denervation.

\section{Biochemical analysis}

Plasma and urine sodium, potassium and lithium concentrations were measured by flame photometry, while the creatinine and protein concentrations were determined spectrophotometrically by the alkaline picrate and sulfosalicylic acid methods, respectively.

\section{Statistics and calculations}

The results are reported as means \pm SEM per $100 \mathrm{~g}$ body weight. Renal clearance (C) was calculated by a standard formula $(\mathrm{C}=$ $\mathrm{UV} / \mathrm{P}$ ) using the plasma creatinine and lithium levels for each period. Creatinine clearance was used to estimate glomerular filtration rate and lithium clearance $\left(\mathrm{CLi}^{+}\right)$ was used to assess proximal tubule output. Fractional sodium $\left(\mathrm{FENa}^{+}\right)$and potassium $\left(\mathrm{FEK}^{+}\right.$) excretions were calculated as $\mathrm{CNa}^{+} /$ $\mathrm{CCr}$ and $\mathrm{CK}^{+} / \mathrm{CCr}$, respectively, where $\mathrm{CNa}^{+}$ and $\mathrm{CK}^{+}$are the ion clearances and $\mathrm{CCr}$ is the creatinine clearance. The fractional proximal $\left(\mathrm{FEPNa}^{+}\right)$and post-proximal $\left(\mathrm{FEPPNa}{ }^{+}\right)$ sodium excretions were calculated as $\mathrm{CLi}^{+} /$ $\mathrm{CCr} \times 100$ and $\mathrm{CNa}^{+} / \mathrm{CLI}^{+} \times 100$, respectively $(18,19)$. Changes in fractional excretion were estimated using the values from sham-operated rats. Statistical analysis of the data was performed by one-way analysis of variance for repeated measurements. When the results were significant, Bonferroni's contrast test was used to determine the extent of the differences. A $P$ value $<0.05$ was considered to indicate significance.

\section{Results}

Figures 1 and 2 show the effects of LNAME treatment and renal denervation on 
renal function and arterial blood pressure. All rats survived and were clinically healthy up to the 21st day of the study. Although all groups gained weight during the study, the gain in L-NAME-treated rats tended to level off by the last week (Figure 1). Proteinuria

Table 1 - Effect of the oral administration of vehicle (group I, GI), or L-NAME (GII) to sham-operated rats on body weight, renal weight and serum sodium, potassium and lithium levels compared to similar vehicle (GIII) or L-NAME (GIV) administration to bilaterally renal denervated rats.

The data are reported as the means \pm SEM for 10 rats per group. There were no statistically significant differences in the parameters studied (ANOVA and Bonferroni's contrast test).

\begin{tabular}{lcccccc}
\hline Groups & $\begin{array}{c}\text { Body } \\
\text { weight (g) }\end{array}$ & $\begin{array}{c}\text { Renal } \\
\text { weight (g) }\end{array}$ & $\begin{array}{c}\text { Liquid intake } \\
(\mathrm{ml})\end{array}$ & $\begin{array}{c}\mathrm{Na}^{+} \\
(\mathrm{mM})\end{array}$ & $\begin{array}{c}\mathrm{K}^{+} \\
(\mathrm{mM})\end{array}$ & $\begin{array}{c}\mathrm{Li}^{+} \\
(\mu \mathrm{M})\end{array}$ \\
\hline $\mathrm{GI}$ & $300 \pm 15$ & $1.46 \pm 0.05$ & $34.9 \pm 0.9$ & $143 \pm 0.9$ & $3.7 \pm 0.1$ & $107 \pm 5.0$ \\
GII & $289 \pm 16$ & $1.40 \pm 0.05$ & $34.8 \pm 0.5$ & $142 \pm 1.2$ & $4.5 \pm 0.1$ & $117 \pm 6.0$ \\
GIII & $291 \pm 19$ & $1.33 \pm 0.05$ & $35.7 \pm 0.7$ & $143 \pm 0.4$ & $4.4 \pm 0.1$ & $109 \pm 8.0$ \\
GIV & $302 \pm 14$ & $1.37 \pm 0.06$ & $33.8 \pm 0.9$ & $145 \pm 0.7$ & $4.3 \pm 0.2$ & $110 \pm 7.2$
\end{tabular}
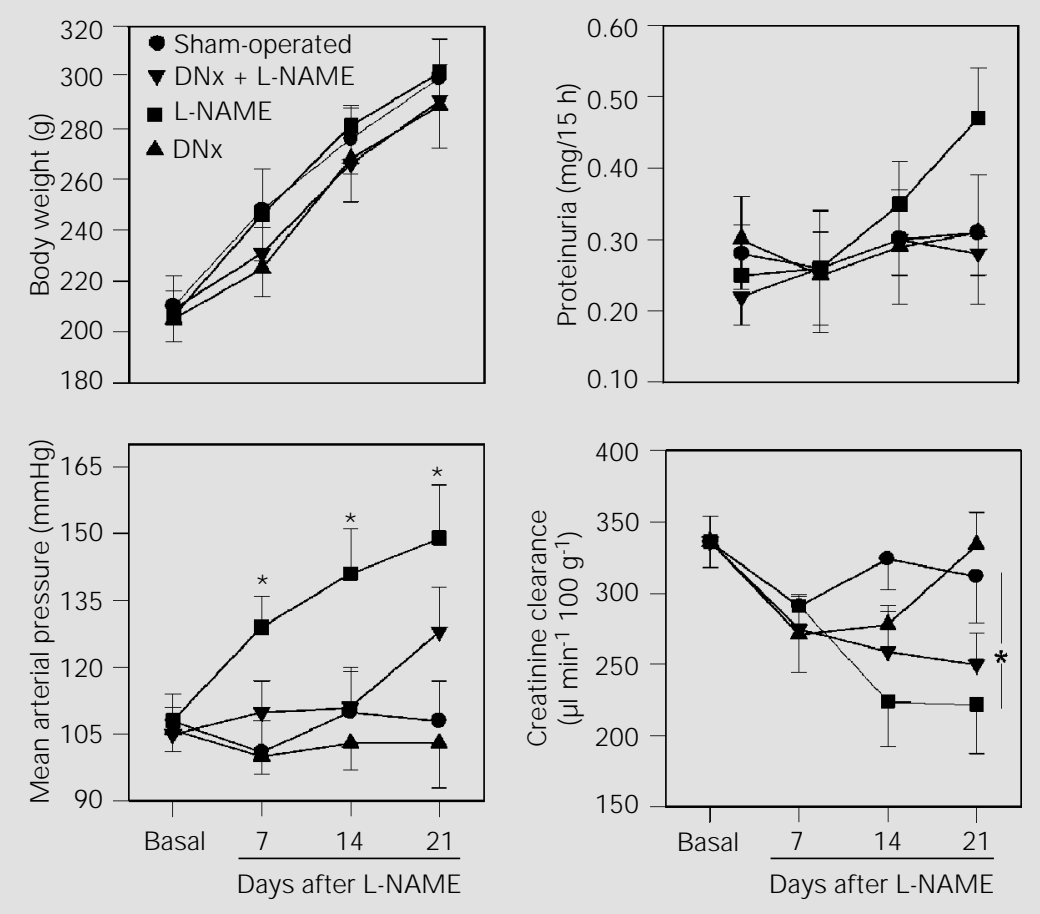

Figure 1 - Effect of oral L-NAME administration on body weight, proteinuria, mean arterial pressure and renal creatinine clearance in sham-operated rats compared to bilaterally renal denervated (DNx) rats. The data are reported as the mean \pm SEM for 10 rats per group. $* \mathrm{P}<0.05$ compared to the sham-operated vehicle-treated or sham-operated L-NAME-treated rats (ANOVA and Bonferroni's contrast test). was similar in all groups during the first week but increased in sham-operated LNAME-treated rats from the second week onwards (Figure 1). By the end of the third week, proteinuria was significantly higher in these rats than in the other three groups. There were no significant differences in daily solid rat chow intake (median: $22.7 \mathrm{~g}$, range: 15.3 to $31.2 \mathrm{~g}$ ) or serum potassium, sodium and lithium levels between sham-operated rats and the other groups (Table 1).

Basal blood pressure did not differ significantly among the four groups. After 1 week, arterial pressure was significantly increased in sham-operated L-NAME-treated rats compared with the other groups and reached $149 \pm 12 \mathrm{mmHg}$ by week 3 compared to $108 \pm 6.0 \mathrm{mmHg}$ in sham-operated vehicle-treated rats $(\mathrm{P}<0.05)$ (Figure 2$)$. Arterial pressure did not change significantly in the other groups during the three weeks of the study (Figure 1).

Urinary flow rates did not differ significantly among the groups during the study of renal tubule sodium handling. Glomerular filtration rate estimated by $\mathrm{CCr}$ decreased significantly from $336 \pm 18$ to $222 \pm 59 \mu \mathrm{l}$

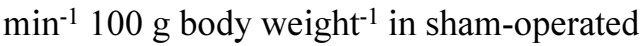
L-NAME-treated rats and from $329 \pm 20.3$ to $250 \pm 22 \mu 1 \mathrm{~min}^{-1} 100 \mathrm{~g}$ body weight ${ }^{-1}$ in denervated L-NAME-treated animals (Figure 2). Creatinine clearance dropped transiently in denervated rats between weeks 1 and 2 after renal denervation but returned to basal levels by the third week. Creatinine clearance was $315 \pm 19 \mu 1 \mathrm{~min}^{-1} 100 \mathrm{~g}$ body weight $^{-1}$ in the vehicle-infused rats and remained unchanged throughout the experiment. Basal renal fractional sodium and potassium excretion did not differ among the experimental groups. L-NAME significantly increased $\mathrm{FENa}^{+}$and $\mathrm{FEK}^{+}$excretion from 7 to 21 days post-treatment (Figure 2) and this increase was accompanied by a significant increase in post-proximal sodium excretion compared to the sham-operated vehicletreated rats (Figure 2). This increase oc- 
curred despite a significant fall in $\mathrm{CCr}$ (Figure 1). Although $\mathrm{CCr}$ decreased transiently between 7 and 14 days, urinary sodium and potassium excretion was unchanged in renal denervated rats compared to basal values and sham-denervated rats.

The high urinary sodium and potassium excretion observed in sham-operated LNAME-treated rats was enhanced by bilateral renal denervation after 7 to 21 days of LNAME treatment. This enhanced fractional excretion was associated with a significant increase in proximal and post-proximal sodium excretion compared to the other groups (Figure 2). As also observed in the L-NAMEtreated group, the rise in ion excretion was associated with a significant fall in CCr.

\section{Discussion}

The present experiments tested the hypothesis that the arterial hypertension induced by NOS inhibition is related, at least in part, to changes in renal nerve activity and renal sodium excretion. Our results agree with previous studies which have demonstrated that long-term oral administration of LNAME results in a marked and sustained rise in arterial blood pressure associated with an increase in urinary sodium excretion $(7,13,14,20)$. In addition, NOS inhibition enhanced urinary sodium excretion by increasing post-proximal tubule sodium rejection despite a decrease in glomerular filtration rate (Figure 1) and in the proportion of sodium load filtered.

The inhibition of NO synthesis may influence tubular reabsorption by a direct effect on tubular sodium transport or by hemodynamically mediated mechanisms involving a reduction in medullary blood flow or a rise in renal interstitial hydrostatic pressure $(21,22)$. In support of a direct action of NO is the study by Stoos et al. (23) which showed that NO directly inhibited sodium transport in cultured cortical collecting duct cells. Mattson and colleagues (22) also reported that NOS inhibition decreased papillary plasma flow. These changes in intrarenal hemodynamics may play an important role in mediating the altered sodium handling induced by L-NAME.

Previous studies which examined the effects of systemic NOS inhibition on sodium excretion have yielded mixed results perhaps because of differences in the experimental methods and doses of L-NAME used, type of anesthesia, and the activity of endogenous vasoconstrictor systems. These factors could influence the extent to which renal perfusion pressure and renal vascular resistance responded to the inhibition of $\mathrm{NO}$ synthesis, thus affecting sodium excretion. Baylis et al. (15) reported that bolus intravenous injection of $\mathrm{N}^{\mathrm{G}}$-monomethyl arginine (NMMA) (100 mg) increased sodium excre-

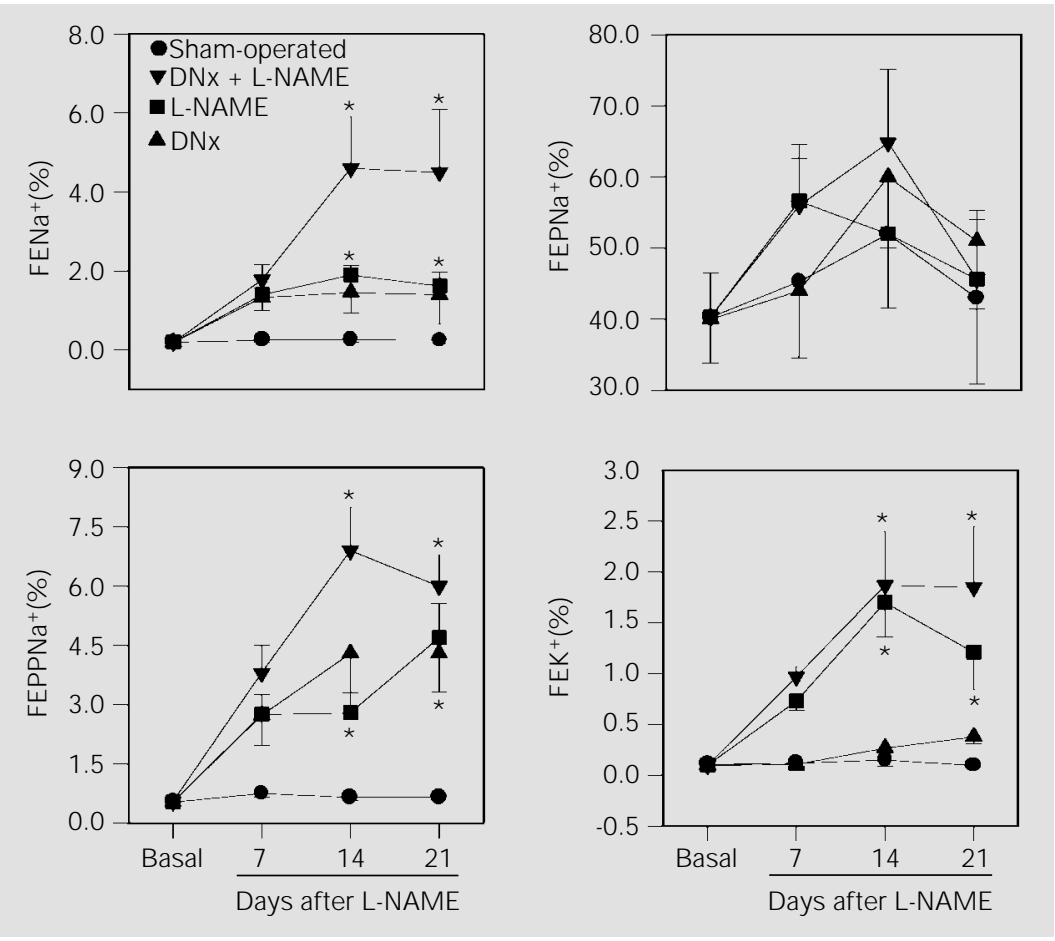

Figure 2 - Effect of oral L-NAME administration on fractional sodium $\left(\mathrm{FENa}^{+}\right)$and potassium $\left(\mathrm{FEK}^{+}\right)$excretion, and fractional proximal $\left(\mathrm{FEPNa}^{+}\right)$and post-proximal $\left(\mathrm{FEPPNa}{ }^{+}\right)$tubule sodium excretion in sham-operated rats compared to bilaterally renal denervated (DNx) rats. The data are reported as the mean \pm SEM for 10 rats per group. $* \mathrm{P}<0.05$ compared to the sham-operated vehicle-treated or sham-operated L-NAME-treated animals (ANOVA and Bonferroni's contrast test). 
tion whereas bolus injection of L-NAME $(10 \mathrm{mg})$ did not effect natriuresis. Lahera et al. (16) examined the effect of different doses of L-NAME on natriuresis. In rats receiving $1 \mathrm{mg} \mathrm{kg}^{-1} \mathrm{~min}^{-1}$, an anti-natriuretic response occurred with no changes in mean arterial pressure, renal plasma flow or glomerular filtration rate. In contrast, the infusion of 50 $\mathrm{mg} \mathrm{kg}{ }^{-1} \mathrm{~min}^{-1}$ significantly increased arterial pressure and was accompanied by an early progressive fall in renal blood flow and glomerular filtration with no change in renal sodium excretion.

These results suggest that the inhibition of NOS can directly and transiently enhance sodium reabsorption in post-proximal nephron segments. However, at larger doses such as that used in our experiments, L-NAME produced increases in arterial pressure that overrode the initial anti-natriuretic effect. In agreement with this observation, Madrid et al. (20) reported that a high dose of L-NAME increased $\mathrm{UNaV}$ and $\mathrm{FENa}^{+}$in rats, whereas a low dose of L-NAME reduced renal sodium excretion and blunted pressure natriuresis only in rats with innervated kidneys.

NO synthase inhibitors have been reported to decrease glomerular filtration rate in some studies (8), but not in others (14). Although neither renal blood flow nor renal vascular resistance was measured in the present study, glomerular filtration rate decreased following L-NAME administration, suggesting afferent arteriole vasoconstriction. Previous studies have demonstrated that LNAME decreases renal blood flow without changing glomerular filtration (24). These observations imply that NO inhibition may selectively increase postglomerular renal vascular resistance.

The precise mechanism underlying the chronic hypertension induced by NOS inhibition has not been identified. The long-term control of arterial pressure is thought to be dominated by the renal control of fluid and electrolyte balance $(25,26)$. However, as pointed out above, the sodium balance has been reported to be near normal (27) or even positive (28) during chronic administration of NOS inhibitors, despite a significant elevation in renal perfusion pressure.

The present findings show that renal denervation markedly delayed and possibly attenuated the L-NAME-induced increase in arterial pressure (Figure 1) associated with an additional rise in post-proximal sodium rejection. Thus, chronic L-NAME-induced hypertension in renal denervated rats may be dependent on an anti-natriuretic neural effect that blunts the renal pressure natriuresis induced by the rise in blood pressure. Complete renal denervation delays the rise in blood pressure in other rat models of hypertension, including spontaneously hypertensive and New Zealand rat strains and hypertension induced by angiotensin-II (29). However, negative results have been reported for salt-sensitive Dahl rats and the effect of renal denervation in preventing hypertension in the DOCA-salt and the one-kidney, oneclip models is controversial (29).

The salient findings of the present study suggest that the increase in arterial pressure after NOS inhibition is partly mediated by renal nerve activity. Sakuma et al. (30) showed that intravenous administration of the NO synthesis inhibitor increased renal sympathetic nerve activity. Spinal sectioning but not by vagotomy or sinoartic baroreceptor denervation abolished this effect. The injection of NO synthesis inhibitors intracisternally (31) and directly into the nucleus tractus solitarius (32) and rostral ventrolateral medulla (33) also increases arterial pressure and renal sympathetic nerve activity. NO may be involved in brain stem regulation of sympathetic nerve activity and NO inhibitors may influence the renal control of sodium excretion and arterial pressure via this pathway.

Although the rationale for renal denervation has generally been to interrupt sympathetic nerve activity directed at the kidney, denervation of the renal plexus also deprives 
the kidney of its sensory innervation. Selective renal afferent nerves may have remarkably widespread effects on the renorenal sympathetic reflexes and urinary sodium excretion $(34,35)$. Selective renal afferent denervation attenuates hypertension in the one-kidney, one-clip model and causes a small reduction in blood pressure in spontaneously hypertensive rats (35). However, selective afferent denervation had no effect on the development of hypertension in spontaneously hypertensive rats during renal wrap hypertension or during hypertension caused by the infusion of norepinephrine into the renal artery (35). Since our experiments were not specifically designed to distinguish be- tween the effects of efferent and afferent renal denervation, we cannot discount an influence of afferent renal nerves on our results. Although the precise mechanism responsible for the subsequent rise in arterial pressure in renal denervated rats treated with L-NAME is still not clear, our study suggests that bilateral renal denervation delayed and possibly attenuated L-NAME-induced hypertension by promoting an additional decrease of tubule sodium reabsorption in the post-proximal segments of nephrons. Much of the hypertension caused by chronic NO synthesis inhibition is thus dependent on renal nerve activity.

\section{References}

1. Furchgott RF (1983). Role of endothelium in response of vascular smooth muscle. Circulation Research, 53: 557-573.

2. Vanhoutte PM, Rubanyi GM, Miller VM \& Houston DS (1986). Modulation of vascular smooth muscle contraction by endothelium. Annual Review of Physiology, 48: 307-320.

3. Blythe WB \& Maddux FW (1991). Hypertension as a causative diagnosis in patients entering end-stage renal disease program in the United States from 19801986. American J ournal of Kidney Diseases, 18: 33-37.

4. Dworkin ID \& Feiner HD (1986). Glomerular injury in uninephrectomized spontaneously hypertensive rats: a consequence of glomerular capillary hypertension. J ournal of Clinical Investigation, 77: 797-809.

5. Hostetter TH, Olson J L, Rennke HG, Venkatachalam M \& Brenner BM (1981). Hyperfiltration in remnant nephrons: a potential adverse response to renal ablation. American J ournal of Physiology, 241: F85F92.

6. Kumagai $K$, Suzuki $H$, Ichikawa $M$, J imbo M, Ryuzaki M \& Saruta T (1994). Nitric oxide increases renal blood flow by interacting with the sympathetic nervous system. Hypertension, 24: 220-226.

7. Majid DAS, Williams A, Kadowitz PJ \& Navar G (1993). Renal responses to intraarterial administration of nitric oxide donor in dogs. Hypertension, 22: 535-541.

8. Nakamura T, Alberola AM \& Granger JP (1993). Role of renal interstitial pressure as a mediator of sodium retention during systemic blockage of nitric oxide. Hypertension, 21: 956-960.

9. Hansen J, Jacobsen TN \& Victor RG (1994). Is nitric oxide involved in the tonic inhibition of central sympathetic outflow in humans? Hypertension, 24: 439-444.

10. Kumagai $H$, Averill DB, Khosla MC \& Ferrario CM (1993). Role of nitric oxide and angiotensin II in the regulation of sympathetic nerve activity in spontaneously hypertensive rats. Hypertension, 21: 476484.

11. Knoblich PR, Freeman RH \& Villarreal D (1996). Pressure-dependent renin releases during chronic blockage of nitric oxide synthase. Hypertension, 28: 738742.

12. Erlich $Y \& \&$ Rosenthal $T$ (1996). Contribution of nitric oxide to the beneficial effects of enalapril in the fructose-induced hyperinsulinemic rat. Hypertension, 28: 754-757.

13. Matsuoka $H$, Nishida $H$, Nomura G, Van Vliet BN \& Toshima H (1994). Hypertension induced by nitric oxide synthesis inhibition is renal nerve dependent. Hypertension, 23: 971-975.

14. Majid DAS, Williams A \& Navar G (1993). Inhibition of nitric oxide synthesis attenuates pressure-induced natriuretic responses in anesthetized dogs. American J ournal of Physiology, 264: F79-F87.

15. Baylis C, Harton P \& Engels K (1990). Endothelium-derived relaxing factors control renal hemodynamics in normal rat kid- ney. J ournal of the American Society of Nephrology, 1: 875-881.

16. Lahera V, Salom MG, Miranda-Guardiola F, Moncada S \& Romero JC (1991). Effects of NG-nitro-L-arginine methyl ester on renal function and blood pressure. American J ournal of Physiology, 261: F1033-F1037.

17. Bello-Reuss E, Colindres RE, PastorizaMuños E, Mueller RA \& Gottschalk CW (1975). Effects of acute unilateral renal denervation in the rat. J ournal of Clinical Investigation, 56: 208-217.

18. Quadros MR, Gontijo J AR \& Figueiredo J F (1996). Renal tubular sodium handling determined by lithium clearance in partially hepatectomized rats. Brazilian J ournal of Medical and Biological Research, 29: 1077-1083.

19. Menegon LF, Figueiredo J F \& Gontijo J AR (1999). Effect of chronic metabolic acidosis on renal growth and renal sodium handling in uninephrectomized rats. Renal Failure, 21: 13-22.

20. Madrid MI, Salom MG, Tornel J , Lopez E \& Fenoy FJ (1998). Interactions between nitric oxide and renal nerves on pressurenatriuresis and natriuresis. J ournal of the American Society of Nephrology, 9: 15881595.

21. Granger J P (1986). Regulation of sodium excretion by renal interstitial hydrostatic pressure. Federation Proceedings, 45: 2892-2896.

22. Mattson DL, Roman RJ \& Cowley J r AW (1992). Role of nitric oxide in renal papil- 
lary blood flow and sodium excretion. Hypertension, 19: 766-769.

23. Stoos BA, Carretero AO \& Garvin J L (1991). Endothelium-derived relaxing factor inhibits transport in cultured cortical collecting duct cells. Hypertension, 18: 390 (Abstract).

24. Majid DAS \& Navar G (1992). Suppression of blood flow auto-regulation plateau during nitric oxide blockage in canine kidney. American J ournal of Physiology, 262: F40F46.

25. Guyton AC (1990). Long-term arterial blood pressure control: an analysis from animal experiments and computer and graphic models. American J ournal of Physiology, 259: R865-R877.

26. Guyton AC, Coleman TG, Cowley J r AW, Manning J r RD, Norman RA \& Ferguson J D (1974). A system analysis approach to understanding long-range arterial blood pressure control and hypertension. Circulation Research, 35: 159-176.
27. Manning J $r$ RD, $\mathrm{Hu} L$, Mizelle $\mathrm{HL} \&$ Granger J P (1993). Role of nitric oxide in long-term angiotensin II-induced renal vasoconstriction. Hypertension, 21: 949955.

28. Salazar FJ , Alberola A, Pinilla J M, Romero C \& Quisada T (1993). Salt-induced increase in arterial pressure during nitric oxide synthesis inhibition. Hypertension, 22: 49-55.

29. Van Vliet BN, Hall JE, Lohmeier TE \& Mizelle HL (1994). Renal circulation. In: Bennett T \& Gardiner S (Editors), Nervous Control of Blood Vessels. Harwood Academic Publishers, Philadelphia.

30. Sakuma II, Togashi H, Yoshida M, Saito H, Tamura M, Kobayashi T, Yasuda H, Gross SS \& Levi R (1992). NG-Methyl-L-arginine, an inhibitor of L-arginine-derived nitric oxide synthesis, stimulates renal sympathetic tone? Circulation Research, 70: 607-611.

31. Togashi H, Sakuma I, Yoshiota M,
Kobayashi T, Yasuda H, Kitabataki A, Saito H, Gross SS \& Levi R (1992). A central action of nitric oxide in blood pressure regulation. J ournal of Pharmacology and Experimental Therapeutics, 262: 343-347.

32. Harada S, Tokunaga S, Monohara M, Masaki H, Tagawa T, Imaizumi $\mathrm{T} \&$ Takeshita A (1993). Inhibition of nitric oxide formation in the nucleus tractus solitarius. Circulation Research, 72: 511-516.

33. Shapoval LN, Sagach VF \& Pobegailo LS (1991). Nitric oxide influences ventro-lateral medullary mechanisms of vasomotor control in the cat. Neuroscience Letters, 132: 47-50.

34. Gontijo J R, Smith LA \& Kopp UC (1999). CGRP activates renal pelvic substance $P$ receptors by retarding substance $P$ metabolism. Hypertension, 33: 493-498.

35. Kopp UC (1993). Renorenal reflexes in hypertension. J ournal of Hypertension, 11: 765-773. 